\title{
Influence of gas-to-particle partitioning on the hygroscopic and droplet activation behaviour of $\alpha$-pinene secondary organic aerosol
}

\author{
Zsófia Jurányi ${ }^{1}$, Martin Gysel ${ }^{1}$, Jonathan Duplissy ${ }^{1}$, Ernest Weingartner ${ }^{1}$, Torsten Tritscher ${ }^{1}$, Josef \\ Dommen $^{1}$, Silvia Henning ${ }^{2}$, Markus Ziese ${ }^{2}$, Alexej Kiselev ${ }^{2}$, Frank Stratmann ${ }^{2}$, Ingrid George ${ }^{3}$ and Urs \\ Baltensperger ${ }^{1}$
}

\author{
${ }^{1}$ Laboratory of Atmospheric Chemistry, Paul Scherrer Institut, Villigen, Switzerland \\ ${ }^{2}$ Leibniz-Institute for Tropospheric Research, Leipzig, Germany \\ ${ }^{3}$ Department of Chemistry, University of Toronto, 80 St. George Street, Toronto, ON M5S 3H6
}

Hygroscopic properties of secondary organic aerosol (SOA) formed by photooxidation of different concentrations (10-27 or 220-270 ppb) of $\alpha$-pinene precursor was investigated at different relative humidities (RH) using a hygroscopicity tandem differential mobility analyzer (HTDMA, RH $=95-97 \%$ ) and using the mobile version of the Leipzig Aerosol Cloud Interaction Simulator (LACISmobile, RH = 98-99.3\%). In addition, the cloud condensation nuclei (CCN) activity was measured applying two CCN counters (CCNC). An apparent single-hygroscopicity parameter kappa of $\sim 0.09, \sim 0.07-0.13$, and $\sim 0.02-0.04$ was derived from CCNC, HTDMA and LACIS data, respectively, assuming surface tension of pure water. Closure between HTDMA and CCNC data was achieved within experimental uncertainty, whereas closure between LACIS and CCNC was only achieved with assuming a concentration dependent surface tension reduction, consequently resulting in lower CCNC derived kappa values. Comparing different experimental techniques at varying precursor concentration in more detail reveals further open questions. Varying precursor concentration influences hygroscopic growth factors at subsaturated RH, while it has no effect on the CCN activation. This difference in behaviour might be caused by precursor concentration dependent surface tension depression or changing droplet solution concentration dependence of the water activity coefficient with varying SOA composition. Furthermore, evidence was found that the SOA might need several seconds to reach the equilibrium growth factor at high $\mathrm{RH}$.

\section{Introduction}

Atmospheric aerosols may influence the Earth's radiation balance in several ways. Direct aerosol effects occur through scattering and absorption of light. Water uptake can modify the size and the refractive index of the particles and therefore has an influence on this effect. Aerosol particles acting as cloud condensation nuclei $(\mathrm{CCN})$ can alter cloud properties and thus cause radiative forcing through changes of the cloud albedo, ${ }^{1}$ cloud lifetime, ${ }^{2}$ etc., commonly referred to as indirect aerosol effects on climate. The sum of these effects partially counteract with the warming effect of the greenhouse gases. However, the exact magnitude and global distribution of these effects is still poorly understood. ${ }^{3}$

Organic matter is a major constituent of atmospheric aerosol, besides inorganic salts, dust and elemental carbon. ${ }^{4}$ It is either directly emitted into the atmosphere as primary particles, or formed by oxidation of precursor gases, resulting in low vapour pressure compounds which nucleate or condense onto existing particles as secondary organic aerosol (SOA). Numerous sources, precursor gases and reaction pathways result in a vast number of individual organic compounds in atmospheric aerosols. ${ }^{5}$ The hygroscopic and $\mathrm{CCN}$ properties of atmospheric organic matter are much less understood than those of the inorganic salts.

Either hygroscopicity ${ }^{6,7}$ or CCN activity ${ }^{8-10}$ of monoterpene derived SOA has been studied previously, demonstrating its ability to take up water and act as CCN. Much less studies are available that compare the water uptake with the activation process. Prenni et al. ${ }^{6}$ found that the measured $\mathrm{CCN}$ activation properties of SOA produced by ozonolysis of different monoterpenes were inconsistent with hygroscopicity measurements below water saturation using Köhler theory expressions with several water activity parameterizations. Duplissy et al. ${ }^{11}$ presented a study on the importance of the initial precursor concentration ( $\alpha$-pinene, a representative of biogenic emissions) on the chemical properties and the water uptake below saturation of the nucleating SOA. They also found good agreement between the measured hygroscopic properties and $\mathrm{CCN}$ activation for low precursor gas concentrations. Motivated by this inconsistency between different studies, we employed three different measurement techniques in order to probe growth curves at different points including high relative humidities (RH) as close as possible to water saturation and also at the point of $\mathrm{CCN}$ activation. A second focus was laid on the effects of varying initial precursor concentration on $\mathrm{CCN}$ properties which to our knowledge was not investigated before.

\section{Experimental}

\subsection{SOA formation}

Photooxidation experiments were carried out in a $27-\mathrm{m}^{3}$ Teflon reaction chamber at $20{ }^{\circ} \mathrm{C}$ and $50-60 \% \mathrm{RH}^{12}$ The chamber was first humidified before introducing $\mathrm{NO}$ and $\mathrm{NO}_{2}$. A known amount of $\alpha$-pinene was evaporated in a heated glass sampling bulb and flushed with pure air into the chamber and allowed to equilibrate for 30 minutes resulting in a known precursor concentration, which was checked in some experiments by a proton transfer reaction mass spectrometer (PTR-MS). A previous study ${ }^{13}$ at the PSI chamber showed a reproducibility of the measured initial precursor concentration of $\pm 10 \%$ when the same amount of precursor was added.

A constant ratio $(2: 1)$ of $\alpha$-pinene to nitrogen oxides $\left(\mathrm{NO}_{\mathrm{x}}\right)$ was used in order to remain in the same photochemical regime. Four xenon arc lamps (16 kW total) simulating the solar light spectrum were used to drive the photochemistry.

Mainly two types of experiments were performed. The precursor concentration was varied between atmospherically

\section{This document is the accepted manuscript version of the following article:}

Jurányi, Z., Gyse1, M., Duplissy, J., Weingartner, E., Tritscher, T., Dommen, J., ... Baltensperger, U. (2009). Influence of gas-to-particle partitioning on the hygroscopic and droplet activation behaviour of $\alpha$-pinene secondary organic aerosol. Physical chemistry Chemical Physics, 11(36), 8091-8097. https://doi.org/10.1039/b904162a 
relevant (10-27 ppb) and about one order of magnitude higher values $(220-270 \mathrm{ppb})$. The experiments of both types were repeated several times in order to assure reproducibility of the measurements. In both the high and low concentration experiments the initially high NO concentrations decreased rapidly within an hour and nucleation occurred when NO levels became low. We assume that the chemical composition of gas phase oxidation products is similar in both types of experiments and that the chemical composition of SOA is determined by the gas to particle partitioning of semi-volatile species.

\subsection{CCNC}

Two identical continuous-flow streamwise thermal-gradient $\mathrm{CCN}$ counters (DMT-CCNC) ${ }^{13}$ were used to determine the size dependent critical supersaturation $\left(\mathrm{SS}_{\text {crit }}\right)$ of the particles. The calibration of the CCNCs was verified every 2-4 days by using nebulized, size selected (with a differential mobility analyzer, DMA) ammonium sulphate particles. ${ }^{14}$ The relative deviations between the individual calibrations were less than 5\%, which is considered to be the accuracy of the supersaturation (SS) in our experiments. The main reason for using two CCNCs was to improve time resolution and counting statistics.

The SOA sampled from the chamber was first dried using a silica gel diffusion drier and then brought to charge equilibrium with a bipolar ${ }^{85} \mathrm{Kr}$ charger, before a quasi-monodisperse size was selected using a DMA, which was operated at 10:1 sheath to aerosol flow ratio. The monodisperse sample flow was then split up into four branches in order to measure the total particle number concentration $(\mathrm{CN})$ and $\mathrm{CCN}$ concentration with two condensation particle counters (CPC; TSI model 3010 and 3022A) and two CCNCs (DMT model CCN-100), respectively. The aerosol had a residence time of $\sim 9 \mathrm{~s}$ in the CCNC, during which the aerosol can take up water and activate. The ratio of $\mathrm{CCN}$ to $\mathrm{CN}$ concentration as function of SS for a certain dry diameter, hereinafter referred to as activated fraction (AF) spectrum, was recorded by stepping the SS set in the CCNC.

The chamber SOA is internally mixed such that the activation of singly and doubly charged particles is clearly separated on the SS-scale, and the AF spectrum has two well-defined steps with a plateau in between (Fig. 1). Note that the doubly charged particles with equal electrical mobility as the singly charged ones are larger in diameter and therefore activate at lower SS. The range of set $\mathrm{SS}$ was chosen to capture the $\mathrm{AF}$ spectrum from the plateau up to complete activation of all particles (Fig. 1). A sigmoid function was then fitted to the measured $\mathrm{AF}$ spectrum between the plateau and complete activation and $\mathrm{SS}_{\text {crit }}$ was obtained from the half-rise position. Potential biases arising from doubly charged particles, different particle losses in the sampling lines from DMA to CPC and CCNC or different counting efficiencies of CPC and CCNC are accounted for with this approach, because the difference between the plateau and complete activation corresponds to all singly charged particles. Note that the size distribution of chamber SOA is typically narrow and thus the number fraction of doubly charged particles can be very high if the diameter set at the DMA is below the mode of the size distribution (see example shown with triangles in Fig. 1)

\subsection{HTDMA}

A hygroscopicity tandem differential mobility analyzer (HTDMA) was used to measure diameter growth factors (GF) at well defined RH compared to the particle dry size $D_{0}$. A detailed description of the measurement principle and instrument is given in Duplissy et al. ${ }^{15}$ Briefly, the chamber aerosol is dried with a silica gel diffusion drier and brought to charge equilibrium using a ${ }^{85} \mathrm{Kr}$ bipolar charger before selecting a quasi monodisperse size cut in DMA1. These particles of well defined dry size are in a first step humidified in a temperature controlled box at $24{ }^{\circ} \mathrm{C}$, before they pass into another box cooled to $20^{\circ} \mathrm{C}$, thus resulting in a further RH increase to the target value of typically $97 \%$. The particles experience the target $\mathrm{RH}$ for approximately $15 \mathrm{~s}$ before the resulting equilibrium diameter is measured by scanning the relevant diameter range with a second DMA, also kept at the target RH, adding additional 7s of residence time, and a CPC. The raw data were inverted with the TDMAinv inversion algorithm. ${ }^{16}$ Measurement uncertainties mainly arise from RH with an accuracy of $\pm 1.2 \% \mathrm{RH}$ at $\mathrm{RH}=97 \%$, while the determination of small GFs is highly accurate with an uncertainty of $\Delta \mathrm{GF}= \pm 0.02$. The dry size investigated by the CCNCs and the HTDMA was coordinated and gradually increased in order to follow the mode of the growing particle number size distribution in time.

\subsection{LACIS}

The mobile version of the Leipzig Aerosol Cloud Interaction Simulator (LACIS) was used for this study, here we present results from this instrument for the first time. Its setup is similar to the long version, described in detail by Stratmann et al. ${ }^{17}$. The mobile version of LACIS consists of a flow tube $(0.8 \mathrm{~m}$ in length). Aerosol and sheath air were humidified (aerosol: $\mathrm{MH}-$ 110-12S-4, sheath air: PH-30T-24KS, Perma Pure) to well defined dew point temperatures (reproducibility $\sim 0.03 \mathrm{~K}$ ) before entering the flow tube. The dew point temperatures and the wall temperature of the flow tube determine the water vapour saturation in the flow tube. For the hygroscopic growth measurements LACIS was operated in its sub-saturated mode. ${ }^{19}$ In this mode the wall temperature $\left(20^{\circ} \mathrm{C}\right)$ is above the dew point temperatures (between $18.75^{\circ} \mathrm{C}$ and $19.95{ }^{\circ} \mathrm{C}$ ) of aerosol and sheath air. The aerosol sample experiences a high relative humidity during a residence time of $\sim 6.2 \mathrm{~s}$ in total. First the dry aerosol is humidified to a set dew-point and experiences $100 \%$ $\mathrm{RH}$ for $\sim 1.5 \mathrm{~s}$ in the humidifier of LACIS. Behind the humidifier, the RH is not controlled for around $2 \mathrm{~s}$ until the aerosol enters the inlet. In the inlet and flow tube the aerosol particles have $\sim 2.7 \mathrm{~s}$ residence time to equilibrate their water content at the controlled target $\mathrm{RH}$.

The size of the grown particles is measured with a white light optical particle spectrometer at the exit of the flow tube. ${ }^{19}$ For the investigations presented here, the spectrometer was calibrated several times during the campaign using polystyrene latex (PSL) particles of 6 different sizes between 240 and $1020 \mathrm{~nm}$ (Duke Scientific). The refractive index used to retrieve the droplet size from the measured scattered light intensities was 1.45 for dry SOA particles. When determining the sizes of the hydrated SOA particles, the changing refractive index due to water absorption with increasing size was taken into account by using a volume 
mixing rule. ${ }^{19}$ Ammonium sulphate particles were used to check the relative humidity in LACIS. These calibration measurements were repeated every two days and showed a high stability and reproducibility during the campaign.

\section{Theory}

The equilibrium diameter $D_{e q}$ of an aqueous solution droplet at a certain RH is described by the Köhler theory ${ }^{20}$ :

$$
\mathrm{RH}=a_{w} \cdot \exp \left(\frac{4 \sigma_{s} v_{w}}{R T D_{e q}}\right)
$$

where $a_{w}$ is the water activity, $\sigma_{s}$ is the surface tension of the solution, $v_{w}$ is the partial molar volume of water, and $R$ and $T$ are the universal gas constant and the temperature. Eqn (1) describes the behaviour of the solution droplet for the whole saturation region.

We used a semi-empirical model describing the concentration dependence of the water activity with a single hygroscopicity parameter $\kappa$. This parameterization was introduced by Petters and Kreidenweis $^{21}$ :

$$
\frac{1}{a_{w}}=1+\kappa \frac{V_{s}}{V_{w}}
$$

where $V_{s}$ is the solute volume (dry particle volume), $V_{w}$ the water volume, and $\kappa$ the hygroscopicity parameter. A higher $\kappa$ value means higher hygroscopicity. The most hygroscopic species found in ambient aerosols have a maximum $\kappa$ of $\sim 1.3, \kappa=0$ means that the particle is not water soluble, though possibly wettable.

The activation of a solution droplet to a cloud droplet occurs at $\mathrm{RH}$ equal to or larger than the maximum of eq. (1). Under the assumption that at the point of activation the dry particle volume is negligible compared to the total volume $\left(V_{w} \approx V_{s}+V_{w}\right)$ and using the fact that $\exp (x) \approx 1+x$ if $x<<1$, eqn (1) can be solved analytically for $\mathrm{SS}_{\text {crit }}$, resulting in the following dry diameter dependence:

$$
\mathrm{SS}_{c r i t}=\mathrm{RH}_{\max }-1=\left(\frac{256 \sigma_{s}^{3} v_{w}^{3}}{27 \kappa R^{3} T^{3}}\right)^{\frac{1}{2}} D_{0}^{-\frac{3}{2}}
$$

The various assumptions involved here are discussed in Sects. 4.2 and 5. All $\kappa$ values presented in the following are derived from HTDMA, LACIS or CCNC data under the assumption of surface tension of pure water.

\section{Results}

\subsection{SOA properties}

During the experiments the maximum SOA mass concentrations were $10-15 \mu \mathrm{g} / \mathrm{m}^{3}$ and $200-300 \mu \mathrm{g} / \mathrm{m}^{3}$ when using $10-27 \mathrm{ppb}$ to $220-270 \mathrm{ppb} \alpha$-pinene precursor concentrations, respectively. These mass concentrations were calculated from the measured dry number size distributions assuming spherical particles with a density of $1.3 \mathrm{~g} / \mathrm{cm}^{3}{ }^{22}$ SOA formed from such different initial precursor concentration has different physical and chemical properties. ${ }^{11,23}$ A higher initial precursor gas concentration results in an over-proportionally increased SOA mass concentration because a higher fraction of volatile, less oxidised species partitions into the aerosol phase, ${ }^{24}$ reflected in a concurrent decrease of the oxygen to carbon ratio. ${ }^{25}$

\subsection{Hygroscopic and $\mathrm{CCN}$ properties}

The influence of the different precursor concentrations is reflected in the GF measured by the HTDMA. For the low and high concentration experiments, GFs of $\sim 1.63$ and $\sim 1.43$ were determined, respectively at $\mathrm{RH}=97 \% \pm 1.2 \%$ and $D_{0}=200 \mathrm{~nm}$ $\sim 5$ hours after lights were switched on (not shown). This corresponds to $\kappa$ values of $0.126 \pm 0.042$ and $0.074 \pm 0.025$, which can be seen in Figs. 2 and 3. Particle hygroscopicity was slightly increasing with photochemical age (i.e. with the elapsed time after lights on). On average, $\kappa$ values were increasing with $\mathrm{d} \kappa / \mathrm{dt}=2.1 \cdot 10^{-3} \pm 0.7 \cdot 10^{-3}$ and $2.4 \cdot 10^{-3} \pm 0.4 \cdot 10^{-3}$ hour $^{-1}$ for low and high precursor concentration, respectively.

For the low precursor concentration experiments only few particles grew above the lower cut-off size of the optical particle counter (OPC) used as the size detector in LACIS, thus data were only available towards the end of these experiments. The measured GFs at $99 \%$ RH were significantly smaller than those of the HTDMA at lower RH: $1.45 \pm 0.06$ and $1.25 \pm 0.07$ at low (average of all available data points) and high (measured $\sim 5$ hours after lights were switched on) precursor concentration, respectively, for particles with $D_{0}=200 \mathrm{~nm}$, which corresponds to $\kappa$ values of $0.036 \pm 0.005$ and $0.018 \pm 0.006$. Possible reasons for this discrepancy are discussed in Sect. 5.1. For the high concentration experiments this $\kappa$ value stayed almost constant with time $\left(\mathrm{d} \kappa / \mathrm{dt}=0.94 \cdot 10^{-3} \pm 0.4 \cdot 10^{-3}\right.$ hour $\left.^{-1}\right)$ during more than 12 hours of measurement; because of the above mentioned lower cut-off limitations no such calculation was performed for low concentrations (see Figs. 2 and 3). LACIS derived $\kappa$ values were less dependent on the precursor concentration than those derived from the HTDMA.

The CCN-derived average $\kappa$ values measured after 5 hours were $0.091 \pm 0.010$ and $0.092 \pm 0.009$ for the low and high precursor concentration (Figs. 2 and 3), respectively. The photochemical aging effect was hardly detectable, with average values of $\mathrm{d} \kappa / \mathrm{dt}=0.69 \cdot 10^{-3} \pm 0.7 \cdot 10^{-3}$ and $0.79 \cdot 10^{-3} \pm 0.4 \cdot 10^{-3}$ hour $^{-1}$ for low and high precursor concentration, respectively, which is significantly less than observed by the HTDMA instrument. A summary of the observed CCN properties is presented in Fig. 4, where the measured $\mathrm{SS}_{\text {crit }}$ is plotted against the dry diameter on logarithmic scales. Data are available for dry diameters between $D_{0}=100$ and $230 \mathrm{~nm}$. No complete scans could be performed during the first 1.5 to 2 hours after starting the photooxidation experiments due to the fast growth of the modal diameter of the SOA particles following nucleation, thus imposing the lower size limit of $\sim 100 \mathrm{~nm}$. The upper limit is given by the minimum supersaturation in the CCNC. Every data point in Fig. 4 is the average of all available measurements at the corresponding dry size and precursor concentration. Measurements taken at any time after switching the lights on are included because no distinct temporal trend of $\mathrm{CCN}$ properties was observed. No significant 
difference between the $\mathrm{CCN}$ activity measured at high or low precursor concentration was found. In both cases the data points are lying on a line on the $\log (\mathrm{SS})$ versus $\log (D)$ plot. This line corresponds to $\kappa=0.10$, assuming surface tension of pure water, which is in good agreement with the results from Prenni et al. ${ }^{6}$, whereas they reported much smaller hygroscopic growth factors compared to the results of this study. Engelhart et al. ${ }^{8}$ found somewhat higher $\mathrm{CCN}$ derived $\kappa$ values $(\approx 0.15)$. However, these two studies investigated ozonolysis of $\alpha$-pinene, which may be the reason for some discrepancies to our findings.

The line fitted to the data in Fig. 4 has a slope of -1.53 which is very close to the predicted value of -1.5 and therefore follows the introduced simplified Köhler theory. A different slope or a bend in the curve would indicate additional dry diameter dependence such as a limited solubility at the point of activation, a concentration dependent surface tension, or a size dependent chemical composition. ${ }^{26}$ Therefore we have no indication of such phenomena, but we have to note that they might appear at sizes smaller than the ones measured here. The fact that the SOA seems to be completely dissolved at the point of activation even at the smallest investigated dry diameter $(100 \mathrm{~nm})$, allows us to give an estimate of the SOA's minimum water solubility. The solution concentration at the point of activation was calculated from the critical droplet diameter, using eqns (1) and (2) and assuming a solute density of $1.3 \mathrm{~g} / \mathrm{cm}^{3,22}$ resulting in a water solubility of at least $23 \mathrm{~g} / \mathrm{kg}$ at $\sim 30^{\circ} \mathrm{C}$.

\section{Discussion}

\subsection{Disagreement between HTDMA and LACIS}

As one can see in Figs. 2 and 3 for both precursor concentrations, $\kappa$ values derived from the LACIS (originating from GF measurements at $\mathrm{RH} \approx 99 \% \mathrm{RH}$ ) are significantly lower than the HTDMA (at $\mathrm{RH} \approx 95-97 \%$ ) and CCNC (at $\mathrm{RH}>100 \%$ ) derived $\kappa$. The question is, if this discrepancy is due to a real aerosol property or caused by some instrumental malfunctioning or other artefacts.

We had no indication of any instrumental malfunctioning. The HTDMA and LACIS were tested by measuring the growth of nebulized ammonium sulphate (which was also used to calibrate the CCNCs) resulting in very good agreement with each other at the overlapping $\mathrm{RH}$ region and with theoretical values ${ }^{27}$. As additional control a nebulized single component organic substance, citric acid, was measured with all instruments resulting in similar $\kappa$ values, and GF measurements agreed well with previous measurements ${ }^{28}$. The RH accuracy of LACIS was further validated by deliquescence measurements of succinic acid.

The simplification in the $\kappa$ model of assuming a concentration independent $\kappa$ value can be excluded as the reason for the observed discrepancies since the $\mathrm{RH}$ range covered by the instruments overlapped at $\mathrm{RH}$ around $97 \%$, still giving different GFs (HTDMA 1.45, LACIS 1.15).

SOA consists of many semi-volatile species that are in equilibrium with the surrounding gas phase. If this gas phase is modified, the partitioning will change resulting in evaporation of or condensation into the aerosol phase, therefore evaporation artefacts may influence our measurements. The DMAs of the HTDMA consist of closed sheath air loops, so in an ideal case the sheath air gas phase would equilibrate with the sample air gas phase even though equilibration time might be rather high. Further tests included dry measurements with the HTDMA, where the whole instrument was kept at a constant dry RH. Evaporation or condensation artefacts in between the first and second DMA would result GF $<1$ or GF $>1$, respectively, bearing in mind that there is no change in the water content at constant dry RH. These tests resulted in $\mathrm{GF}=1$ for $\mathrm{SOA}$, indicating the absence of such partitioning artefacts in the HTDMA.

The CCNC uses filtered sample air for the sheath flow in the growth column so the partitioning may mainly change because of the elevated temperature $\left(\sim 30^{\circ} \mathrm{C}\right)$ in the instrument. To find out if such an effect plays a role, a charcoal denuder (which removes the gas phase and therefore changes the partitioning) was placed in the sampling line upstream of the CCNC instrument and downstream of the drier at one of the CCNCs. The test was started 5 hours after the light was switched on when the aerosol size distribution was not changing significantly any more and lasted 6 hours. In an alternating sequence of three SS scans each with and without denuder, always at $200 \mathrm{~nm}$ dry size no significant change was seen in the measured $\mathrm{SS}_{\text {crit }}$. This indicates that the produced SOA was not very volatile but of course this does not prove that evaporation did not occur in LACIS $\left(\sim 20^{\circ} \mathrm{C}\right)$ which was operated with an open loop sheath air flow system with particle free compressed air, or in the HTDMA $\left(\sim 20^{\circ} \mathrm{C}\right)$ which had a longer residence time.

Another hypothesis is that the aerosols might not reach equilibrium in some instruments if the residence time at RH near the well-regulated target $\mathrm{RH}$ is too low. Pure inorganic species are normally reaching the equilibrium state very fast $(<1 \mathrm{~s})$, but there are indications that organic and mixed organic/inorganic aerosols can show kinetic limitations. Equilibration times of up to $40 \mathrm{~s}$ were observed by Sjogren et al. ${ }^{29}$ for specific mixtures of ammonium sulphate with adipic acid or humic like substances. A HTDMA intercomparison study performed at the same smogchamber using the same precursor showed that the higher residence time of the instrument, the higher the measured GF. ${ }^{15}$ During water uptake the particles undergo different processes. As discussed by Sjogren et $a l .{ }^{29}$ the diffusion of water vapour to the particle surface is a very fast process, and one has to assume a very low water accommodation coefficient such that the transfer across the gas-particle interface becomes the limiting factor. If the particle is liquid, the diffusion in the liquid phase is again fast. The limiting part can be the dissolution of large molecules (possibly oligomers ${ }^{30}$ ), or aqueous phase chemistry that might change the hygroscopic properties of the aerosol.

We assume that the particles have sufficient time to reach their equilibrium GF in the HTDMA used in this study. The residence time in the CCNC is shorter than in the HTDMA, however, temporarily adding a nafion prehumidifier upstream of the CCNC, offering extra $\sim 12$ s residence time at $\mathrm{RH}>90 \%$, had no effect on the measured $\mathrm{SS}_{\text {crit }}$ at either precursor concentration. Therefore we also assume that the $\mathrm{SS}_{\text {crit }}$ measured by CCNC is not influenced by residence time limitations. LACIS had the shortest residence time of all instruments. It cannot be excluded that the equilibrium GF is not reached in LACIS due to slowly 
dissolving compounds, which would cause the observed discrepancies between HTDMA and LACIS. It should be noted that GFs measured by a HTDMA and LACIS were in agreement with each other in the study by Wex et al. ${ }^{35}$, which is in contrast to the experiments reported here. Future measurements should also focus on determining the necessary equilibration times for the different types of SOA, using instruments with variable residence time.

\subsection{Hygroscopicity closure}

Based on the above discussion we assume that water uptake and $\mathrm{CCN}$ activation measured by HTDMA and CCNCs, respectively, were not influenced by a limited residence time, therefore we attempt to perform a closure study between these two instruments; as an alternative approach we also try to link the LACIS and CCNC data.

The HTDMA and CCNC derived $\kappa$ values agree within the experimental uncertainties, thus hygroscopicity closure can be achieved with the one-parameter $\kappa$ model and assuming surface tension of pure water at both precursor concentrations. The HTDMA measurements showed that the lower the precursor concentration, the higher is the measured GF and therefore the derived $\kappa$ value. This confirms previous findings reported by Duplissy et al. ${ }^{11}$. A small precursor concentration dependence is also seen in the LACIS derived $\kappa$ values, though on a lower level. Based on these results one would also expect a precursor concentration dependence of $\mathrm{CCN}$ properties too, as predicted in the work of Duplissy et al. ${ }^{11}$. However, in this study the CCN properties were found to be independent of the precursor concentration, thus turning the $\mathrm{CCN}$ properties predicted in Duplissy et al. ${ }^{11}$ for high precursor concentrations invalid. A first hypothesis explaining this result is that a surface tension reduction occurring only at the high precursor concentration compensates for the effect of reduced hygroscopicity. Organics may indeed lower the surface tension ${ }^{31}$.

Calculations were done to find out which value of the surface tension is needed to reach a perfect agreement between the HTDMA and CCNC derived $\kappa$ values. We used the parameterization scheme described in Ziese et al. ${ }^{32}$. Additional to the parameterization of the water activity, as described before, the surface tension is parameterized by means of the Szyszkowski equation $^{33}$. The scheme works iteratively; deducing the water activity from the hygroscopic growth measurements (in the first step the surface tension of water is assumed in the Kelvin term) and applying this value to gain the Szyszkowski-parameter, which describes the surface tension. The new surface tension is applied to deduce the water activity until convergence is reached. This yielded $0.0859 \mathrm{~J} / \mathrm{m}^{2}$ for the low precursor concentration and $0.0681 \mathrm{~J} / \mathrm{m}^{2}$ for the high concentration at the point of activation. It is very unlikely for organic substances to have a higher surface tension than the value of pure water $\left(0.071 \mathrm{~J} / \mathrm{m}^{2}\right.$ at $\left.\mathrm{T}=30^{\circ} \mathrm{C}\right)$ but the above value lies within the measurement uncertainty and a systematic error of $1 \%$ in the HTDMA RH could explain the difference. Thus we can state that a $20 \%$ surface tension depression from low to high precursor concentration is enough to explain the different trends.

As an alternative approach, the same surface tension parameterization as above was applied to the LACIS and CCNC data. Closure between LACIS and CCNC was achieved for a surface tension at the point of activation of $0.0578 \mathrm{~J} / \mathrm{m}^{2}$ for the low concentration experiments and of $0.0553 \mathrm{~J} / \mathrm{m}^{2}$ for high concentration experiments, and corresponding CCNC derived $\kappa$ values decrease to $\sim 0.045$ and $\sim 0.036$, respectively. These values agree with reported surface tensions of SOA generated by the ozonolysis of $\alpha$-pinene at higher initial concentrations. ${ }^{32,} 33$ It has to be noted that the bulk surface tension corresponding to the above values inferred for the point of activation would be even lower, if surface to bulk partitioning effects occur.

Our second hypothesis, which is also discussed by Petters et $a l .{ }^{34}$ is a different solute concentration dependence of the water activity ( $\kappa$ value) at the different precursor concentrations (in this hypothesis we assume that the surface tension is equal to that of pure water). This special behaviour of the water activity ( $\kappa$ value) could originate either from non-ideal solution effects not considered in the simplified $\kappa$ model or from effects of limited solubility.

It was shown that a decreased precursor concentration results in an increased degree of oxidation of the SOA. ${ }^{11,25}$ Petters et $a l .{ }^{34}$ reported for SOA produced by ozonolysis of $\alpha$-pinene with and without $\mathrm{OH}$-scavenger that the degree of oxidation has a strong influence on GFs observed at $\mathrm{RH}<98 \%$, whereas it has very little influence on $\mathrm{CCN}$ activation at $\mathrm{RH}>100 \%$. This means for their system that non-ideal solution behaviour turns the assumption of constant $\kappa$ (eqn 2 ) invalid, which could also apply to our high precursor concentration experiments.

Alternatively, concentration dependent $\kappa$ values in the high precursor concentration case could also be caused by a fraction of sparingly soluble SOA. This would result in complex Köhler curves as shown in Fig. 1 in Petters and Kreidenweis ${ }^{36}$. We performed a simple calculation by assuming that undissolved material is present at the RH of the HTDMA measurements, whereas complete dissolution is assumed at the point of $\mathrm{CCN}$ activation. The difference in HTDMA-derived $\kappa$ values between the high and low precursor concentration case corresponds to a $40 \%$ larger volume fraction of sparingly soluble material in the former case.

In the above two hypotheses either $\kappa$ or the surface tension was assumed to be constant while the other parameter was assumed to be concentration dependent. We have to note that the observations can also be explained by a weaker concentration dependence of both parameters.

\section{Conclusions}

It has previously been shown that the degree of oxidation and the hygroscopic growth at subsaturated $\mathrm{RH}$ of SOA formed by photooxidation of $\alpha$-pinene decreases with increasing precursor concentration. This study confirms previous findings and - by providing CCN measurements for high precursor concentration shows that neither precursor concentration nor photochemical aging has a distinct effect on $\mathrm{CCN}$ activation, contrary to previous anticipation. ${ }^{11}$

Several hypothetical reasons for the observed difference between the influence of the degree of oxidation on the behaviour of SOA at sub- and supersaturated RH have been discussed, including the potential influence of surface active compounds, non-ideal solution behaviour, limited solubility, and residence time effects 
at high RH. However, further investigations are needed to test these hypotheses due to the complexity of the SOA's chemical nature. A sound understanding of the hygroscopic behaviour of SOA is important in order to understand whether and to what extent atmospheric aging, partitioning effects and the degree of oxidation are relevant to atmospheric effects and processes occurring at sub- and supersaturated conditions.

\section{Acknowledgement}

We would like to thank René Richter for his technical assistance. Financial support by INTROP, EUROCHAMP, MeteoSwiss in the framework of the Global Atmosphere Watch program, the Swiss National Science Foundation and the Centre for Global Change Science is gratefully acknowledged.

\section{References}

1. 2. S. A. Twomey, Atmos. Env., 1974, 8, 1251-1256.

2. B. A. Albrecht, Science, 1989, 245, 1227-1230.

3. IPCC, S. Solomon, D. Qin, M. Manning, M. Marquis, K. Averyt, M. M. B. Tignor, H. L. J. Miller and Z. Chen (eds.), Climate Change 2007 - The Physical Science Basis, Cambridge University Press, Cambridge, 2007.

4. Q. Zhang, J. L. Jimenez, M. R. Canagaratna, J. D. Allan, H. Coe, I. Ulbrich, M. R. Alfarra, A. Takami, A. M. Middlebrook, Y. L. Sun, K. Dzepina, E. Dunlea, K. Docherty, P. F. DeCarlo, D. Salcedo, T. Onasch, J. T. Jayne, T. Miyoshi, A. Shimono, S. Hatakeyama, N. Takegawa, Y. Kondo, J. Schneider, F. Drewnick, S. Borrmann, S. Weimer, K. Demerjian, P. Williams, K. Bower, R. Bahreini, L. Cottrell, R. J. Griffin, J. Rautiainen, J. Y. Sun, Y. M. Zhang and D. R. Worsnop, Geophys. Res. Lett., 2007, 34, L13801, doi:13810.11029/12007GL029979.

5. M. Hallquist, J. C. Wenger, U. Baltensperger, Y. Rudich, D. Simpson, M. Claeys, J. Dommen, N. M. Donahue, C. George, A. H. Goldstein, J. F. Hamilton, H. Herrmann, T. Hoffmann, Y. Iinuma, M. Jang, M. Jenkin, J. L. Jimenez, A. Kiendler-Scharr, W. Maenhaut, G. McFiggans, T. F. Mentel, A. Monod, A. S. H. Prevot, J. H. Seinfeld, J. D. Surratt, R. Szmigielski and J. Wildt, Atmos. Chem. Phys., 2009, in press.

6. A. J. Prenni, M. D. Petters, S. M. Kreidenweis, P. J. DeMott and P. J. Ziemann, J. Geophys. Res., 2007, 112, D10223, doi:10210.11029/12006JD007963.

7. V. Varutbangkul, F. J. Brechtel, R. Bahreini, N. L. Ng, M. D. Keywood, J. H. Kroll, R. C. Flagan, J. H. Seinfeld, A. Lee and A. H. Goldstein, Atmos. Chem. Phys., 2006, 6, 2367-2388.

8. G. J. Engelhart, A. Asa-Awuku, A. Nenes and S. N. Pandis, Atmos. Chem. Phys., 2008, 8, 3937-3949.

9. T. M. VanReken, N. L. Ng, R. C. Flagan and J. H. Seinfeld, J. Geophys. Res., 2005, 110, D07206, doi:07210.01029/02004JD005465.

10. K. E. H. Hartz, T. Rosenorn, S. R. Ferchak, T. M. Raymond, M. Bilde, N. M. Donahue and S. N. Pandis, J. Geophys. Res., 2005, 110, D14208, doi:14210.11029/12004JD005754.
11. J. Duplissy, M. Gysel, M. R. Alfarra, J. Dommen, A. Metzger, A. S. H. Prevot, E. Weingartner, A. Laaksonen, T. Raatikainen, N. Good, F. Turner, G. McFiggans and U. Baltensperger, Geophys. Res. Lett., 2008, 35, L03818, doi:03810.01029/02007GL031075.

12. D. Paulsen, J. Dommen, M. Kalberer, A. S. H. Prevot, R. Richter, M. Sax, M. Steinbacher, E. Weingartner and U. Baltensperger, Environ. Sci. Technol., 2005, 39, 2668-2678.

13. G. C. Roberts and A. Nenes, Aerosol Sci. Technol., 2005, 39, 206-221.

14. D. Rose, S. S. Gunthe, E. Mikhailov, G. P. Frank, U. Dusek, M. O. Andreae and U. Poschl, Atmos. Chem. Phys., 2008, 8, 1153-1179.

15. J. Duplissy, M. Gysel, S. Sjogren, N. Meyer, N. Good, L. Kammermann, V. Michaud, R. Weigel, S. Martins dos Santos, C. Gruening, P. Villani, P. Laj, K. Sellegri, A. Metzger, G. McFiggans, G. Wehrle, R. Richter, J. Dommen, Z. Ristovski, U. Baltensperger and E. Weingartner, Atmos. Meas. Techniques., 2009, in press.

16. M. Gysel, G. B. McFiggans and H. Coe, J. Aerosol Sci., 2009, 40, 134-151.

17. F. Stratmann, A. Kiselev, S. Wurzler, M. Wendisch, J. Heintzenberg, R. J. Charlson, K. Diehl, H. Wex and S. Schmidt, J. Atmos. Oceanic Technol., 2004, 21, 876887.

18. H. Wex, A. Kiselev, F. Stratmann, J. Zoboki and F. Brechtel, J. Geophys. Res., 2005, 110, D21212, doi:21210.21029/22004JD005507.

19. A. Kiselev, H. Wex, F. Stratmann, A. Nadeev and D. Karpushenko, Appl. Opt., 2005, 44, 4693-4701.

20. H. Köhler, Trans. Faraday Soc., 1936, 32, 1152-1161.

21. M. D. Petters and S. M. Kreidenweis, Atmos. Chem. Phys., 2007, 7, 1961-1971.

22. M. R. Alfarra, D. Paulsen, M. Gysel, A. A. Garforth, J. Dommen, A. S. H. Prévôt, D. R. Worsnop, U. Baltensperger and H. Coe, Atmos. Chem. Phys., 2006, 6, 5279-5293.

23. M.R. Alfarra, J. Duplissy, A. Metzger, J. Dommen, A.S.H. Prevot, U. Baltensperger, Geophys. Res. Lett., 2009, submitted

24. J. H. Seinfeld and J. F. Pankow, Annual Review of Physical Chemistry, 2003, 54, 121-140.

25. J. E. Shilling, Q. Chen, S. M. King, T. Rosenoern, J. H. Kroll, D. R. Worsnop, P. F. DeCarlo, A. C. Aiken, D. Sueper, J. L. Jimenez, and S. T. Martin, Atmos. Chem. Phys., 2009, 9, 771-782

26. L. T. Padro, A. Asa-Awuku, R. Morrison and A. Nenes, Atmos. Chem. Phys., 2007, 7, 5263-5274.

27. D. O. Topping, G. B. McFiggans and H. Coe, Atmos. Chem. Phys., 2005, 5, 1205-1222.

28. A. A. Zardini, S. Sjogren, C. Marcolli, U. K. Krieger, M. Gysel, E. Weingartner, U. Baltensperger and T. Peter, Atmos. Chem. Phys., 2008, 8, 5589-5601.

29. S. Sjogren, M. Gysel, E. Weingartner, U. Baltensperger, M. J. Cubison, H. Coe, A. Zardini, C. Marcolli, U. K. Krieger and T. Peter, J. Aerosol Sci., 2007, 38, 157-171.

30. Kalberer, M., Paulsen, D., Sax, M., Steinbacher, M., Dommen, J., Prevot, A. S. H., Fisseha, R., Weingartner, E., Frankevich, V., Zenobi, R., and Baltensperger, Science, 2004, 303, 1430-1438.

31. M. C. Facchini, S. Decesari, M. Mircea, S. Fuzzi and G. Loglio, Atmos. Env., 2000, 34, 4853-4857. 
32.

M. Ziese, H. Wex, E. Nilsson, I. Salma, R. Ocskay, T. Hennig, A. Massling and F. Stratmann, Atmos. Chem. Phys., 2008, 8, 1855-1866.

33. B. Szyszkowski, Zeitschrift für physikalische Chemie, 1908, 64, 385-414.

34. M. D. Petters, H. Wex, C. M. Carrico, E. Hallbauer, A. Massling, G. R. McMeeking, L. Poulain, Z. Wu, S. M.
Kreidenweis and F. Stratmann, Atmos. Chem. Phys. Discuss., 2008, 8, 20839-20867.

35. H. Wex, M. D. Petters, C. M. Carrico, E. Hallbauer, A. Massling, G. R. McMeeking, L. Poulain, Z. Wu, S. M. Kreidenweis and F. Stratmann,, Atmos. Chem. Phys. Discuss., 2009, 9, 955-989.

36. M. D. Petters and S. M. Kreidenweis, Atmos. Chem. Phys., 2008, 8, 6273-6279.

\section{Figures}

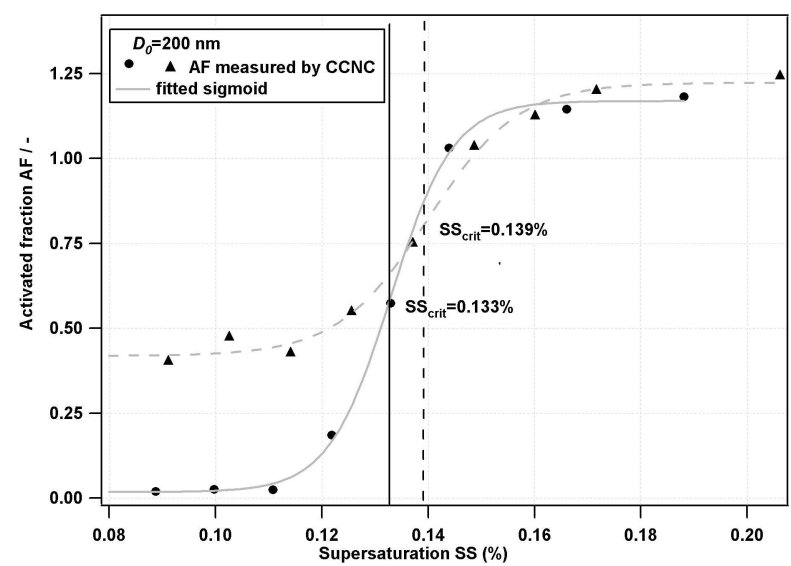

Fig. 1. Determination of $\mathrm{SS}_{\text {crit }}$ (SS at which $50 \%$ of the singly charged particles are activated) in two different cases from the AF spectra: in one case the fraction of the multiple charged particles is negligible (dots and solid line, $220 \mathrm{ppb} \alpha$-pinene, 5 hours after lights on, experiment 10), in the other case it has to be taken into account (triangles and dashed line, $220 \mathrm{ppb} \alpha$-pinene, 6 hours after lights on, experiment 12). The AF reaches higher values than unity, caused by a leaking sheath air filter in the CCNC. This was only discovered later but it did not affect the measured $\mathrm{SS}_{\text {crit }}$.

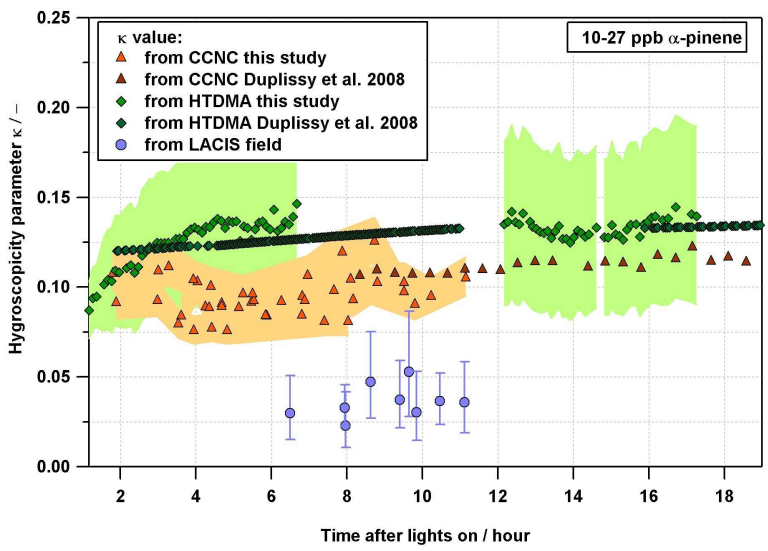

Fig. 2. $\kappa$ values derived from HTDMA, LACIS and CCNC measurements at low $(10-20 \mathrm{ppb})$ precursor concentrations plotted against time elapsed after switching on the lights. Equal symbols are used for both CCN counters because they agree with each other within measurement uncertainty. Propagated measurement uncertainties are shown as shading (HTDMA, CCNC) or error bars (LACIS). This graph includes three independent experiments (LACIS and CCNC), whereas the HTDMA ran only during two of them. The results of this study are in good agreement with a previous study by Duplissy et al. ${ }^{12}$ using the same smogchamber, HTDMA and the same CCNC type (see the filled symbols). The $\kappa$-values are calculated under the assumption of a surface tension of pure water. 


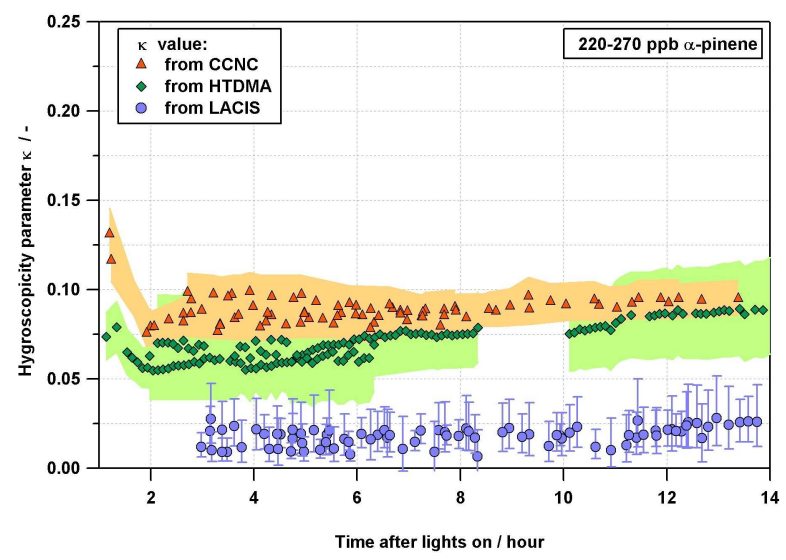

Fig. 3. $\kappa$ values derived from HTDMA, LACIS and CCNC measurements at high (180-240 ppb) precursor concentrations plotted against time elapsed after switching on the lights. Equal symbols are used for both CCN counters because they agree with each other within measurement uncertainty. Propagated measurement uncertainties are shown as shading (HTDMA, CCNC) or error bars (LACIS). This graph includes four independent experiments (LACIS and CCNC), whereas the HTDMA ran only during three of them. The $\kappa$-values are calculated under the assumption of a surface tension of pure water.

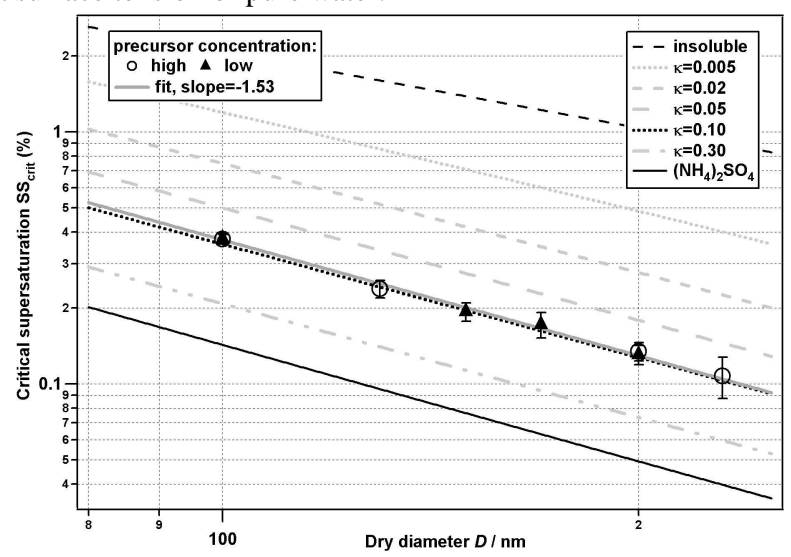

Fig. 4. Critical supersaturation from CCNC measurements plotted against the dry diameter for the low (solid triangle) and high (open circle) precursor experiments on logarithmic scales. One marker and error bar represent the mean and the standard deviation of every measurement that was performed at the corresponding dry diameter. 